\title{
Setting and infrastructure at North Carolina Agricultural and Technical State University
}

\author{
Godfrey A. Uzochukwu*
}

Interdisciplinary Waste Management Institute, Greensboro, North Carolina, USA

\begin{abstract}
North Carolina Agricultural and Technical State University (N.C. A\&T) is an important intellectual and cultural center, and it contributes significantly to improving the quality of life globally. Campus setting and infrastructure provide basic information of the university's consideration towards green environment. Type of higher education institution, climate, campus site, campus setting, campus area, campus ground floor of buildings, campus buildings area, parking area, campus smart buildings, ground cover, drainage systems for reducing soil erosion and runoff, number of students including online students, number of academic faculty and staff and university budget for sustainability have made N.C. A\&T attractive and the university of choice globally for 11,177 students in 2017. The University has one campus site and one university research and training site. Academic buildings occupy about $39 \%$ of main campus area. Buildings account for $40 \%$ of the energy and $72 \%$ of the electricity used in the United States. Buildings also account for $16 \%$ of United States water consumption, $40 \%$ of all material flows and produce up to $40 \%$ of waste in landfills depending on the region. N. C. A\&T is committed to providing more spaces for greenery and safeguarding the environment, as well as developing of sustainable energy solutions.
\end{abstract}

\section{Introduction}

North Carolina Agricultural and Technical State University (N.C. A\&T) is an important intellectual and cultural center, and it contributes significantly to improving the quality of life globally. North Carolina A\&T is one of America's highly respected land-grant universities [5]. The University was founded on principles that embrace setting and infrastructure, student access and quality academic performance that integrates campus sustainability. N.C. A\&T participated in the 2017 world ranking of university sustainability UI GreenMetric and was delighted to showcase the university's programs and innovations in sustainability to the world. Developing a Green Campus relies heavily on setting and infrastructure. N.C. A\&T has invested in cutting-edge sustainable activities and policies that aim to improve setting and infrastructure as well as protect the environment. Setting and infrastructure, a category of UI GreenMetric is a framework for constructing a green university [4]. Global circumstances demand new setting and infrastructure solutions for our science and technical fields, new enhancements in cultural competencies and social awareness, and an uncompromising campus sustainability expectation among students, faculty, staff and administrators. University setting and infrastructure helps to achieve uncompromising campus sustainability. N.C. A\&T has developed important partnerships that impact the social and environmental challenges of regional, national and global communities. The University enhances intellectual environment through creative use of virtual and physical space. (Fig. 1) shows students enjoying the campus setting of N.C.A\&T.

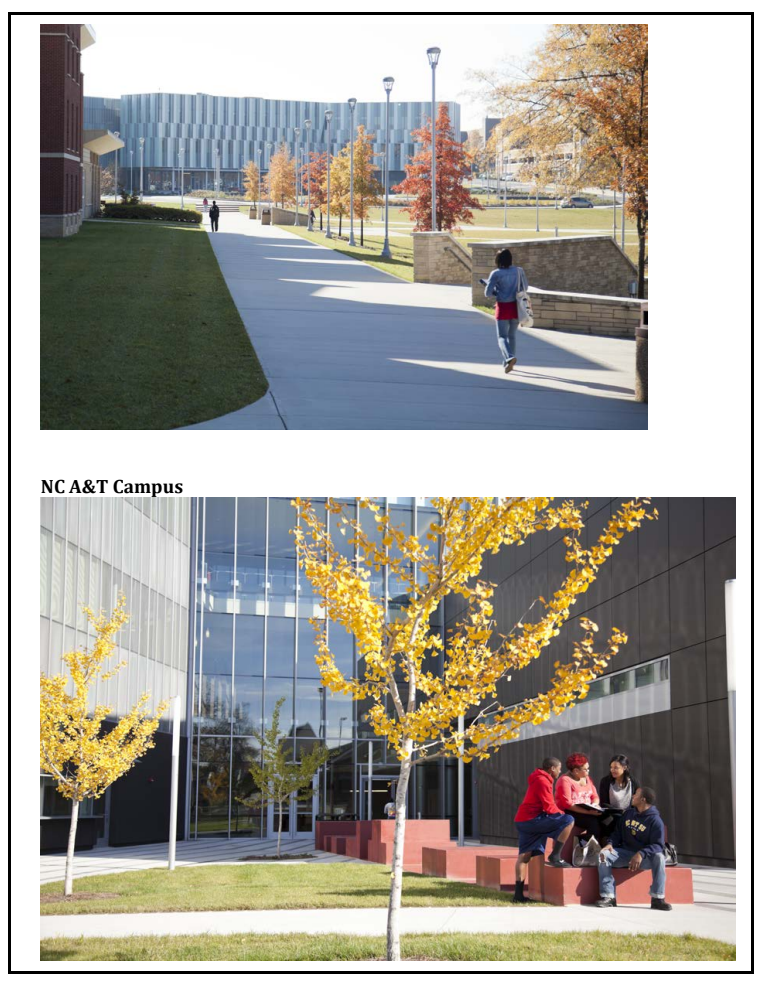

Fig. 1. N.C. A\&T Campus

Campus setting and infrastructure provide basic information of the university's consideration towards

\footnotetext{
* Corresponding author: $\underline{\text { uzo@ncat.edu }}$
} 
green environment. These indicators show whether or not NC A\&T deserves to be called a Green Campus for environmental safeguard.

\section{Methodology}

\subsection{Campus setting}

Campus setting data (Table 1) was collected between August and October 2017 from Facilities Unit, Institutional Research Unit, Budget Office and Division of Research and Economic Development.

Table 1. Campus setting data

\begin{tabular}{|l|l|}
\hline $\begin{array}{l}\text { Type higher } \\
\text { education institution }\end{array}$ & Comprehensive \\
\hline Climate & Humid subtropical \\
\hline Number of campus sites & 1 \\
\hline Main campus setting & Urban \\
\hline Total main campus area & 893,772 (meter square) \\
\hline $\begin{array}{l}\text { University research and } \\
\text { training area }\end{array}$ & $2,428,114$ (meter square) \\
\hline Campus perimeter & 1,751 (meter square) \\
\hline $\begin{array}{l}\text { Total main campus } \\
\text { ground floor of buildings }\end{array}$ & 97,647 (meter square) \\
\hline $\begin{array}{l}\text { Total main campus } \\
\text { buildings area }\end{array}$ & 251,228 (meter square) \\
\hline Total parking area & 74,332 (meter square) \\
\hline $\begin{array}{l}\text { Total main campus smart } \\
\text { buildings }\end{array}$ & 10,347 (meter square) \\
\hline Number of students & 11,177 \\
\hline $\begin{array}{l}\text { Number of online } \\
\text { students }\end{array}$ & 564 \\
\hline $\begin{array}{l}\text { Number of academic } \\
\text { faculty and staff }\end{array}$ & 1,863 \\
\hline $\begin{array}{l}\text { University budget for } \\
\text { sustainability (\%) }\end{array}$ & 15 \\
\hline \multicolumn{2}{|c|}{ of }
\end{tabular}

The University has one campus site and one university research and training site. The total main campus area $(893,772$ meter square or $27 \%$ of total campus area) is devoted to educational activities (Fig. 2). The main campus ground floor of buildings $(97,647$ meter square or $11 \%$ of main campus area) and main campus building area $(251,228$ meter square or $28 \%$ of main campus area) are for instructional activities (Table 1). A large area $(2,428,114$ meter square or $73 \%$ of total campus area) is used for research and training). Academic buildings occupy about $39 \%$ of main campus area. The remaining area is used for parking, green space, sports stadium, etc. N.C A\&T's setting helps to attract and train the next generation of state, national and global workforce.

\subsection{Campus infrastructure}

N.C. A\&T Campus infrastructure highlights adjusting campus master plan to restructuring process of colleges; revamping and modernization of seven (7) existing buildings; creating green spaces and global village; constructing eight (8) new energy and water efficient buildings including Science, Technology, Engineering and Mathematics (STEM) facilities; reimaging sports stadium access; connecting campus to downtown greenway trails and creating a sustainable Information Technology (IT) backbone for N.C A\&T. The University is proactive in the following areas: use of energy efficient appliances in buildings, smart building implementation (New Student Health Center), energy audits, energy monitoring, lighting upgrades, retrocommissioning process for buildings, repair of leaks to reduce metric tons of water renewable energy produced, electricity usage

\subsection{Land use policy}

The University uses land in the most appropriate manner to advance campus sustainability. The main campus area (893,772 meter square) is well managed and used to advance university's mission.

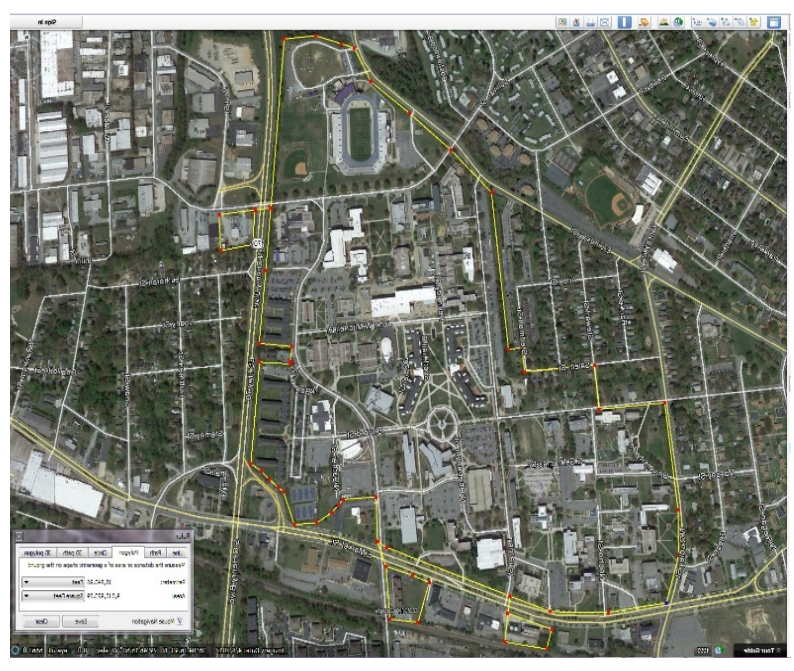

Fig. 2. N.C. A\&T main campus perimeter and area

\section{Summary/ concluding remarks}

Type of higher education institution, climate, campus site, campus setting, campus area, campus ground floor of buildings, campus buildings area, parking area, campus smart buildings, number of students including online students, number of academic faculty and staff and university budget for sustainability have made N.C. A\&T attractive and the university of choice globally for 11,177 students. N. C. A\&T is committed to providing more spaces for greenery and safeguarding the environment, as well as developing of sustainable energy solutions. The University has invested in cutting-edge sustainable activities and policies that aim to improve setting and infrastructure. Buildings account for $40 \%$ of the energy and $72 \%$ of the electricity used in the United States. In addition, buildings account for $16 \%$ of United States water consumption, $40 \%$ of all material flows and produce up to $40 \%$ of waste in landfills depending on the 
region [1]. N.C. A\&T campus is covered with planted grass and tree vegetation year-round for improving air quality, water quality, water absorbance. Drainage systems for reducing soil erosion and runoff are excellent. N.C. A\&T's setting and infrastructure have a positive effect on student choices and institutional selection. Student enrollment increased from 10,852 in 2016 to 11,177 in 2017 ( $3 \%$ increase). Freshman enrollment is up by $11 \%$ for Fall semester 2018 [3]. The University was ranked $6^{\text {th }}$ in 2016 and $7^{\text {th }}$ in 2017 for setting and infrastructure. In addition, the University was ranked $14^{\text {th }}$ overall and $4^{\text {th }}$ in USA for campus sustainability in 2017 [6]. The ranking is an indication of N.C. A\&T's commitment to campus sustainability. University rankings have been shown to affect student choices and institutional selection [2]. The sub-humid tropical climate (Table 1) and urban setting (Fig. 2) make N.C. A\&T an institution of choice for many students globally. The university allocates about $15 \%$ of it's budget to sustainability including setting and infrastructure improvement. The main campus area (893,772 meter square) is well maintained throughout the year. The ground is covered with vegetation to prevent soil erosion and enhance drainage. The ratios of open space to total area and open space to campus population are important to the university for advancing sustainability. A good setting and infrastructure advances education and research. This paper supports the selection of setting and infrastructure as a sub-category for UI GreenMetric ranking because of the impact on energy and climate, waste management, water conservation and management, transportation and education.

N.C. A\&T is striving to become a Green and Sustainable Campus for environmental safeguard.

UI GreenMetric is beneficial to N.C. A\&T for the following reasons:

- Tool for self-assessment of campus sustainability.

- Strong commitment to sustainability issues.
- Help the university's efforts in internationalization and recognition by getting its sustainability efforts on the global map.

- Result in an increase of hits to the university website for campus sustainability

- Increasing awareness of sustainability issues.

- Membership in UI GreenMetric World University Rankings Network

Acknowledgments. The author would like to thank Chancellor Harold L. Martin for his support of campus sustainability, Provost Beryl McEwen and Vice Chancellor Robert Pompey for embracing sustainability. Thanks to N.C. A\&T GreenMetric Team in Facilities unit, Institutional Research and Division of Research and Economic Development for contributing setting and infrastructure data. Special thanks to my colleagues who are advancing sustainability in their classes.

\section{References}

1. Greening Sustainability, North Carolina Agricultural and Technical State University (2012)

2. E. Hazelkorn, The Effects of Rankings on Student Choices and Institutional Selectio, Dublin Institute of Technology (2012)

3. News and Record, Enrollment is up 11\%, News and Record of Greensboro (2018)

4. Nyoman S. and R. F. Sari., Evaluating UI GreenMetric as a tool to support green universities development: assessment of the year 2011 ranking (2011)

5. Preeminence 2020, North Carolina Agricultural and Technical State University (2010)

6. UI GreenMetric, UI GreenMetric World University Rankings (2017) 